\title{
Which dose of haloperidol?
}

\author{
Trudi Hilton, David Taylor and Kathryn Abel
}

Although haloperidol (HAL) has been available as an antipsychotic for over $\mathbf{3 0}$ years, controversy still surrounds the appropriate dose in the treatment of psychosis and in particular, schizophrenia. In practice, high dose HAL (greater than $20 \mathrm{mg} /$ day) continues to be prescribed, despite good reason for not doing so: the incidence of extrapyramidal side-effects (EPSE) is known to be dose-related; and compliance with treatment may be adversely affected by side-effects, especially akathisia and Parkinsonism.

High doses of HAL appear to be used for a variety of reasons: the limited sedation produced may result in higher doses being given when it is felt necessary to 'calm' an agitated patient; doses may be increased in the first few days of therapy when no response has occurred; and current fashion dictates that HAL is prescribed in multiples of $10 \mathrm{mg}$.

The pharmacological argument for lower doses of HAL, therefore, has to be weighted against the clinical requirement for effective treatment. This review evaluates the role of high dose HAL in the treatment of schizophrenia. Recommendations are also made for HAL dosing in different clinical situations.

\section{Current recommended and equivalent doses}

As far as the product licence for HAL (Serenace ${ }^{\mathrm{TM}}$ ) is concerned, dosing recommendations are quite clear: daily doses of 3-9 mg (moderate psychotic symptoms) and 6-15 mg (severe symptoms) are recommended. A maximum dose of $100 \mathrm{mg}$ daily (or rarely $120 \mathrm{mg}$ ) is set for 'resistant' symptoms. The current British National Formulary (BNF, British Medical Association \& Royal Pharmaceutical Society, 1996) cites the same maximum.

Clinicians wishing to switch between neuroleptic medications are presented with many differing equivalent dose comparisons for HAL. For example, in the $B N F$, chlorpromazine $100 \mathrm{mg}$ is said to be equivalent to HAL $2-3 \mathrm{mg}$ (up to $10 \mathrm{mg}$ 'in specialist psychiatric units'); whereas Stephen Bazire (1995) in the Psychotropic Drug Directory cites the equivalence as $\mathrm{HAL} 1.5-5 \mathrm{mg}$. The importance of these kinds of disparity is apparent when considering that a maximum dose of HAL could be calculated as being equivalent to between 2000 and $13000 \mathrm{mg}$ chlorpromazine
(Dewan \& Koss, 1995): a huge range of very large doses.

\section{Comparative dosing studies}

An extensive review comparing results from 19 controlled trials of neuroleptic dosing between 1969-1985 found no evidence to support the use of high dose neuroleptics (Baldessarini et al 1988). In particular, it was concluded that high dosing in the acute phase of lllness did not produce a more rapid response. The following review includes, in an attempt to provide further clarity, all studies since 1990 comparing doses of HAL or HAL-equivalent doses.

Van Putten et al (1990) studied the effect of different doses of HAL in 80 men with schizophrenia. They observed that after the first two weeks of the four-week study, $20 \mathrm{mg}$ HAL was more effective than 5 or $10 \mathrm{mg}$ on one measure of efficacy. However, in the longer term, these investigators found a higher incidence of sideeffects with $20 \mathrm{mg} /$ day HAL despite the use of prophylactic benztropine. They suggested that any superior efficacy of higher dose HAL is rapidly outweighed by a deteriorating side-effect profile. (It should also be noted that the use of anticholinergic medication can reduce the effectlveness of neuroleptics and may itself be associated with an increase in posittve symptoms (Tandon et al, 1990).) In a similar fixed dose study of $20 \mathrm{mg}$ HAL daily for four weeks in $\mathbf{5 0}$ male patients, Harvey et al (1991) found no benefit from increasing the dose to $\mathbf{3 0}$ or $\mathbf{4 0} \mathrm{mg}$ for one week.

In a six-week study, Rifkin et al (1991) compared $10 \mathrm{mg}$ HAL dally with $30 \mathrm{mg}$ and $80 \mathrm{mg}$ in 87 schizophrenic patients. They found $10 \mathrm{mg}$ HAL to be as effective in controlling acute psychotic symptoms as $30 \mathrm{mg}$ or $80 \mathrm{mg}$. No difference in the incidence of side-effects was reported, although all patients did recetve prophylactic benztropine (an anticholinergic).

Different trends in neuroleptic prescribing over the years have led to comparisons of the effects of dosing on longer-term clinical outcome. One retrospective case note comparison of neuroleptic-treated patients in 1976 and 1985 (Vuckovic et al, 1990) revealed that the lengths of stay and outcomes in the groups were similar, but that the mean daily HAL equivalent doses were significantly less in the later group (4.7 mg 
compared to $11.5 \mathrm{mg}$. The authors concluded that higher neuroleptic doses did not improve clinical outcome.

McEvoy et al (1991) introduced the concept of a 'neuroleptic threshold' (NT) in the treatment of schizophrenia. The oral dose of HAL was gradually increased from 0 to $10 \mathrm{mg} /$ day in 106 patients until symptoms of rigidity appeared. The mean NT dose was found to be $3.7 \mathrm{mg} \pm 2.3 \mathrm{mg} /$ day. In the second part of the study (subjects given higher doses or maintained on their NT dose), only the hostility subscale measures were significantly reduced in those whose doses were elevated beyond their NT. No clinical benefit was found in those given higher doses, but more anticholinergic medication was required. Significant increases in the incidence of global sideeffects (bradykinesia, akathisia and dysphoria) were recorded in the high dose groups. Around $70 \%$ of subjects in both treatment groups responded by the end of the five-week study, indicating equal efficacy.

Dose reduction studies are another method of assessing the value of high-dose therapy. Two such studies using scheduled percentage reductions in dose of HAL equivalents over 12 and 32 weeks have been conducted. Both groups of workers reported satisfactory clinical outcomes and relapse rates were relatively low in both studies: 15\% (Van Putten et al, 1993) and 19\% (Leblanc et al, 1994). Clearly more research on the benefits of graded dose reduction is required.

Stone et al (1995) employed the concept of a dose-response threshold for HAL by comparing clinical response to 4,10 and $40 \mathrm{mg} /$ day doses in 24 patients with schizophrenia. They also found no significant difference in clinical response between groups, indicating no benefit from higher doses.

\section{Plasma levels}

Monitoring plasma neuroleptic levels in clinical practice probably has limited value, but has been useful in exploring a possible HAL dose-response relationship. Volavka et al (1990) did not find evidence to support any connection between plasma levels of HAL and clinical improvement. This trial grouped patients $(n=111)$ into three therapeutic ranges by adjusting doses as necessary to achieve 2-13,13.1-24 or $24.1-35 \mathrm{ng} / \mathrm{ml}$. No significant differences in response were seen between these groups (i.e. increasing the blood levels of HAL was of no benefit to the patient).

More recently Volavka et al (1995) revised this study to look at the effect of lower plasma levels ( 2 or $10 \mathrm{ng} / \mathrm{ml}$ ) on the efficacy of HAL. Thirty patients completed the six-week cross-over, double-blind trial. Patients in the lower $(2 \mathrm{ng} /$ ml) plasma level group showed less improvement in positive symptoms than the medium (10 ng/ ml) group, but also less EPSE. The higher plasma-level group suffered a deterioration in negattve symptoms as opposed to an improvement in the $2 \mathrm{ng} / \mathrm{ml}$ group. The authors suggested there was no benefit from levels beyond $12 \mathrm{ng} / \mathrm{ml}$, but that titrating up from zero would reveal clinical responses to levels in the range of 8-12 ng/ml HAL.

In a smaller study ( $n=69$ ), $73 \%$ of patients whose plasma HAL levels were between 5-12 ng/ $\mathrm{ml}$ improved on the Clinical Global Impression Scale after four weeks, compared to approxmately $40 \%$ at levels above and below this range (Midha et al, 1994). Eight patients with higher blood levels, who had their HAL doses titrated down to the lower plasma level, reported improvement in dysphoria, retardation and psychotic symptoms and fewer side-effects. Overall, $50 \%$ of patients 'recovered' regardless of therapeutic level.

Few conclusions can be drawn from these studies. Higher plasma levels appear to be associated with more adverse effects but with no increase in efficacy. Plasma HAL levels may be of most value to confirm compliance or provide some understanding of an individual's handling of HAL.

\section{Antipeschotic efficacy and dopamine blockade}

Blockade of mesolimbic dopamine D2 receptors is thought to underlie the antipsychotic activity of HAL and other neuroleptics. Using positron emission tomography (PET) to assess levels of D2 receptor blockade in the living human brain, investigators have shown that relattvely low dose HAL produces up to $80 \%$ blockade. For example. in a study of 28 patients with a diagnosis of schizophrenia taking a variety of oral or depot neuroleptics, all recorded receptor occupancy of at least $74 \%$. Six were taking oral HAL at doses between 4 and $12 \mathrm{mg} /$ day, and two were given depot medication, $50 \mathrm{mg}$ and $70 \mathrm{mg}$ every 28 days (Farde et al, 1992).

In a more sophisticated PET study, Nyberg et al (1995) compared D2 receptor occupancy with plasma HAL levels in eight patients being successfully treated with low doses of depot HAL (30-50 mg every 28 days, equivalent to $1.5-5 \mathrm{mg}$ orally daily). A mean plasma HAL concentration of $4.6 \mathrm{nmol} / 1$ corresponded to a mean D2 receptor occupancy of $73 \%$ after one week. Immediately before the next dose, occupancy had dropped to a mean of $52 \%$, without any clinical deterioration. All patients remained in remission during the one-year follow-up.

Taken together, these PET data support clinical evidence and plasma monitoring data that no 
further benefit is dertved from HAL doses above $20 \mathrm{mg} /$ day.

\section{Summary and recommendations}

The conclusions of this review are as follows:

- High dose (>20 mg/day) HAL produces no significant, clinically important benefit.

- There is a dose-related increase in adverse effects.

- In non-responders, higher dosing may cause a deterioration in symptoms and quality of life.

- High dose treatment in early acute psychosis does not produce a more rapid response.

- The link between clinical response, HAL dose and plasma level is unclear, but plasma levels may indicate whether a non-responsive patient is compliant or likely to respond to higher doses.

- Given that higher doses are generally not effective, concurrent treatment with benzodiazepines, anticonvulsants or lithium as appropriate, is preferable to increasing the haloperidol dose.

The general recommendations given in Table 1 and more specific clinical guidelines are based on these conclusions.

\section{Clinical guidelines}

All clinical situations must be individually assessed, but the following guidelines are designed to reduce the use of high dose HAL. These examples address some of the common situations facing clinicians.

\section{Acutely disturbed patients needing acute sedation}

We suggest that HAL is not used in this situation because it has poor sedattve properties. Instead consider either droperidol orally or intramuscularly with or without a benzodiazepine such as lorazepam (short-acting) or clonazepam. Alternatively, zuclopenthixol acetate (Acuphase) intramuscularly may be used.

We do not recommend repeated benzodiazepine use beyond 48 hours in the acute phase. Droperidol is not licensed for chronic administration.

\section{Table 1. Recommendations}

- Use HAL only in doses of up to $15 \mathrm{mg} / \mathrm{day}$

- Wait one or two weeks before evaluating the effect of any dose

- Use benzodiazepines if sedation is required.
Acutely disturbed patients not needing acute sedation

This situation is sometimes managed using high dose oral HAL. However, maximum antipsychotic effect is achieved with up to, but not above, $20 \mathrm{mg}$ HAL per day. Note that antipsychotic effect may take up to 2-3 weeks to develop fully. Thus a maximum HAL dose of $10 \mathrm{mg}$ twice a day should be used and this may be augmented with a benzodiazepine: up to $5 \mathrm{mg}$ twice a day diazepam; $1 \mathrm{mg}$ twice a day clonazepam (these should be discontinued gradually after two weeks).

In a clinical situation where benzodiazepines are not considered appropriate, in the acute phase we suggest using droperidol instead of HAL. This should be administered three times daily for up to two weeks with gradual cessation and introduction of HAL equivalent doses (4 mg droperidol = $3 \mathrm{mg}$ HAL).

\section{Patient preferences}

Where patients express a preference for droperidol versus HAL we suggest that it is explained to patients that, because the license for droperidol is limited, doctors are unable to continue long-term prescribing, but that it can be replaced with the most similar compound available (HAL). Clearly. if patients are unhappy with this then alternative neuroleptics may be offered.

\section{Patients who are clinically stable}

If long-term maintenance therapy is appropriate, HAL doses should be gradually titrated down to between 1-10 mg per day, usually in a single daily dose.

\section{Transition between acute and maintenance treatment}

During the transition phase between the acute and more stable clinical condition, when necessary' dosing is often employed. Because it lacks any profound sedattve effects, HAL is not suitable to be used in this way. Instead, droperidol is preferred because it is shorter-acting and more sedative.

Benzodiazepines may also be prescribed when necessary' for short periods with regular review. We suggest either diazepam or clonazepam in the doses above.

\section{References}

Baldessarin, R. T., Cohen, B. M., Teicher, M. H., et al (1988) Significance of neuroleptic dose and plasma level in pharmacological treatment of psychoses. Archives of General Psychiatry. 46, 79-91.

BAzARE, S. (1995) The Psychotropic Drug Directory. Salisbury: Quay Books. 
British Medical association \& The Royal Pharmaceutical SOCIETY (1993) Brttish National Formulary (BNF), No. 26. London: BMA \& The Pharmaceutical Press.

Dewan, M. J. \& Koss, M. (1995) The clinical impact of reported vartance in potency of antipsychotics. Acta Psychiatrica Scandinavica, 81, 229-232.

FARDE, L., NORDSTROM, A.-L., WIESEL, F.-A., et al (1992) Positron emission tomographic analysis of central DI and D2 dopamine receptor occupancy in patients treated with classical neuroleptics and clozapine. Archtues of General Psychiatry, 49, 538-544.

HARVEY, P. D., DAvidson, M., PowCHIK, P., et al (1991) Time course and clinical predictors of treatment response in schizophrenia. Schizophrenia Research, 8, 161-166.

LeBlanc, G., CORMIER, H., GAGNE, M.-A., et al (1994) Effects of neuroleptic reduction in schizophrenic outpatients recetving high doses. Canadian Journal of Psychiatry. 39, 223-229.

McEvoy, J. P., HogarTy, G. E. \& STEngard, S. (1991) Optimal dose of neuroleptic in acute schizophrenta. Archtues of General Psychiatry. 48, 739-745.

MiDHA, K. K., HuBBARD, J. W., MARDER, S. R., et al (1994) Impact of clinical pharmacokinetics on neuroleptic therapy in patients with schizophrenia. Journal of Psychiatry and Neuroscience, 19, 254-264.

NYBERG, S., FARDE, L., HALLDI, C., et al (1995) D2 dopamine receptor occupancy during low-dose treatment with HAL decanoate. American Joumal of Psychiatry. 182. 173-178.

RIFKIN, A., DODDI, S., KARAJG, B., et al (1991) Dosage of HAL for schizophrenia. Archives of General Psychiatry. 48, 166-170.

STONE, C., GARVER, D., GRIFTth, J., et al (1995) Further evidence of a dose-response threshold for HAL in psychosis. American Joumal of Psychiatry. 182. 1210-1212.
TANDON, R. MANn, N. A. EISNER, W. H., et al (1990) Effect of anticholinergic medication on positive and negative symptoms in medication-free schizophrenic patients. Psychiatry Research, 31, 235-241.

The ROYal PHaRmaceutical SOciety Of GReat BRTAnN (1993) Martindale-The Extra Pharmacopoela (30th edn). London: The Pharmaceutical Press.

VAN PUTTEN, T., MARDER, S. R. \& MiNTZ, J. (1990) A controlled dose comparison of HAL in newiy admitted schizophrenic patients. Archives of General Psychiatry. 47. 754-758.

VAN PUTten, T., MARshaln, B. D., LIBERMAN, R., et al (1993) Systematic dosage reduction in treatment-resistant schizophrenic patients. Psychopharmacology Bullettn. 29, 315-320.

Vuckovic, A., Cohen, B., Keck, P., et al (1990) Neuroleptlc dosage regimens in psychotic inpatients: A retrospective comparison. Joumal of Clinical Psychiatry, 81, 107-109.

VOLAVKA, J., COOPER, T. B., MeisNer, M., et al (1990) Dosage effect in psychopharmacology: issues and empirical studies. Psychopharmacology Bulletin. 28, 13-17.

VOLAVKA, J., COOPER, T., JCZOBOR, P., et al (1995) Plasma haloperidol levels and clinical effects in schizophrenia and schizoafiective disorder. Archives of General Psychiatry. 82, 837-845.

Trudi Hilton, Senior Clinical Pharmacist, "David Taylor, Chief Pharmactst; and Kathryn Abel, Senior Registrar, Maudsley Hospital, London SE5 BAZ

*Correspondence 